\title{
Chapter 16 Exploring the Components of Intellectual Capital in Electrical and Electronics SMEs in Pakistan
}

\author{
Muhammad Khalique \\ Universiti Malaysia Sarawak, Malaysia \\ Jamal Abdul Nassir bin Shaari \\ Universiti Malaysia Sarawak, Malaysia \\ Shazali Abu Mansor \\ Universiti Malaysia Sarawak, Malaysia
}

\begin{abstract}
This chapter identifies the existence of the major components of intellectual capital in Small and Medium Enterprises (SMEs) operating in the electrical and electronics manufacturing sector in Pakistan. This study has been designed with the aim of selecting 6 major components of intellectual capital, namely human capital, customer capital, structural capital, social capital, technological capital, and spiritual capital. A structured questionnaire was utilized to conduct a survey of 247 respondents from 106 SMEs to identify the existence of these components of intellectual capital. This study confirms the existence of the major components of intellectual capital in SMEs operating in electrical and electronics manufacturing sector in Pakistan. The findings of this study provide valuable insights on the generalizability of the components of intellectual capital in a novel research setting in Pakistani. The findings of the study allow SMEs practitioners a better understanding about the existence of the components of intellectual capital on which they ought to focus their management efforts in order to take competitive advantage. This study is among only a few to investigate the existence of the components of intellectual capital in Pakistani SMEs and the first to SMEs operating in the electrical and electronics manufacturing sector.
\end{abstract}

DOI: 10.4018/978-1-4666-4753-4.ch016

Copyright $\odot$ 2014, IGI Global. Copying or distributing in print or electronic forms without written permission of IGI Global is prohibited. 